\title{
Antimicrobial Activity of Human Fetal Membranes: From Biological Function to Clinical Use
}

\author{
Taja Železnik Ramuta1, Tina Šket ${ }^{2}$, Marjanca Starčič Erjavec ${ }^{3 *}$ and Mateja Erdani Kreft ${ }^{1 *}$ \\ ${ }^{1}$ Institute of Cell Biology, Faculty of Medicine, University of Ljubljana, Ljubljana, Slovenia, ${ }^{2}$ Department of Synthetic Biology \\ and Immunology, National Institute of Chemistry, Ljubljana, Slovenia, ${ }^{3}$ Department of Biology, Biotechnical Faculty, University \\ of Ljubljana, Ljubljana, Slovenia
}

\section{OPEN ACCESS}

Edited by:

Antonietta Rosa Silini,

Fondazione Poliambulanza Istituto

Ospedaliero, Italy

Reviewed by:

Anna Lange-Consiglio,

University of Milan, Italy

Mathilde Fenelon,

INSERM U1026 Bioingénierie

Tissulaire, France

*Correspondence:

Marjanca Starčič Erjavec

marjanca.starcic.erjavec@bf.uni-Ij.si

Mateja Erdani Kreft

mateja.erdani@mf.uni-lj.si

Specialty section:

This article was submitted to

Tissue Engineering and Regenerative

Medicine,

a section of the journal

Frontiers in Bioengineering and

Biotechnology

Received: 06 April 2021

Accepted: 04 May 2021

Published: 31 May 2021

Citation:

Ramuta TŽ, Šket T, Starčic

Erjavec M and Kreft ME (2021)

Antimicrobial Activity of Human Fetal

Membranes: From Biological Function

to Clinical Use.

Front. Bioeng. Biotechnol. 9:691522.

doi: 10.3389/fbioe.2021.691522
The fetal membranes provide a supportive environment for the growing embryo and later fetus. Due to their versatile properties, the use of fetal membranes in tissue engineering and regenerative medicine is increasing in recent years. Moreover, as microbial infections present a crucial complication in various treatments, their antimicrobial properties are gaining more attention. The antimicrobial peptides (AMPs) are secreted by cells from various perinatal derivatives, including human amnio-chorionic membrane (hACM), human amniotic membrane (hAM), and human chorionic membrane (hCM). By exhibiting antibacterial, antifungal, antiviral, and antiprotozoal activities and immunomodulatory activities, they contribute to ensuring a healthy pregnancy and preventing complications. Several research groups investigated the antimicrobial properties of hACM, hAM, and hCM and their derivatives. These studies advanced basic knowledge of antimicrobial properties of perinatal derivatives and also provided an important insight into the potential of utilizing their antimicrobial properties in a clinical setting. After surveying the studies presenting assays on antimicrobial activity of hACM, hAM, and hCM, we identified several considerations to be taken into account when planning future studies and eventual translation of fetal membranes and their derivatives as antimicrobial agents from bench to bedside. Namely, (1) the standardization of hACM, hAM, and hCM preparation to guarantee rigorous antimicrobial activity, (2) standardization of the antimicrobial susceptibility testing methods to enable comparison of results between various studies, (3) investigation of the antimicrobial properties of fetal membranes and their derivatives in the in vivo setting, and (4) designation of donor criteria that enable the optimal donor selection. By taking these considerations into account, future studies will provide crucial information that will enable reaching the optimal treatment outcomes using the fetal membranes and their derivatives as antimicrobial agents.

Keywords: fetal membrane, perinatal derivatives, amniotic membrane, amnio-chorionic membrane, placenta, antimicrobial peptides, bacteria, antibacterial activity

\section{INTRODUCTION}

Fetal membranes, namely human amnio-chorionic membrane (hACM), human amniotic membrane (hAM) and human chorionic membrane (hCM) have been used in clinic for several decades. hAM has been used most commonly in ophthalmology for ocular surface reconstruction (Riau et al., 2010; Cirman et al., 2014; Malhotra and Jain, 2014; Jirsova and Jones, 2017) and 
in dermatology for treatment of burns, chronic wounds and ulcers (Castellanos et al., 2017; Farhadihosseinabadi et al., 2018). hACM and hCM have also been used to improve wound healing, although less commonly than hAM (Zelen et al., 2015; Tenenhaus, 2017; Kogan et al., 2018). In the last years, progress has been made in the field of basic knowledge regarding the antimicrobial activity of fetal membranes (King et al., 2007a,b; Klaffenbach et al., 2011). Since the use of fetal membranes in tissue engineering and regenerative medicine is increasing (Lim, 2017; Nejad et al., 2021) and microbial infections represent a crucial complication in various treatments (Ikada, 2006; Kuijer et al., 2007; Guo and Dipietro, 2010; Deptuła et al., 2019), antimicrobial properties of fetal membranes are attracting more and more attention. In this review, we focus on the biological function of hACM, hAM, and hCM, their antimicrobial properties, and the potential of their use in clinical applications.

\section{THE BIOLOGICAL FUNCTION OF FETAL MEMBRANES}

The fetal membranes are composed of hAM and hCM. Their role is to surround the embryo and later fetus during gestation and they are crucial for maintaining a pregnancy to delivery (BryantGreenwood, 1998; Verbruggen et al., 2017). Moreover, the amniotic sac is surrounded by outer hCM and hAM on the inside, and together they provide a supportive environment for the growing fetus. hAM is in direct contact with the human amniotic fluid (hAF), in which the embryo or fetus is developing, allowing it to sense and respond to the needs of the fetus. Furthermore, fetal membranes shield the fetus from environmental and endogenous hazards, such as physical, chemical, or biological changes that may harm the fetus (Mamede et al., 2012).

Firstly, the fetal membranes must bear the hydrostatic pressure of the hAF, whose volume changes with gestation from approximately $10 \mathrm{ml}$ at week 8 up to approximately $1000 \mathrm{ml}$ at 34 weeks, and dropping slightly until birth (Brace and Wolf, 1989). In the third trimester, the hAF volume is maintained mainly by regulating the rate of absorption through the amnion into fetal blood. In details, it is controlled based on the ratio of fetal urine component that acts as a stimulator for absorption and a fetal membrane-derived inhibitor (Anderson et al., 2013; Brace et al., 2013, 2018). Secondly, the membranes must also withstand sudden impacts and compresses, for instance from fetal movements and Braxton-Hicks contractions. Although hAM is approximately five times thinner, it is up to ten times stronger and stiffer than hCM (Oxlund et al., 1990). Preterm membranes have been shown to be stronger than term membranes, which is the result of the regulated physiological process of membrane weakening, since the membrane should rupture during labor (Moore et al., 2006; Joyce et al., 2009; Rangaswamy et al., 2011). Thirdly, there is evidence that hAM regulates the $\mathrm{pH}$ of the $\mathrm{hAF}$ by converting bicarbonate to the $\mathrm{CO}_{2}$ with human carbonic anhydrase isoenzymes, which are strongly expressed in human amniotic epithelial cells (hAEC) (Mühlhauser et al., 1994).
Importantly, the hACM normally protects the fetus from pathogens that can directly or indirectly induce dangerous pregnancy complications, namely premature rupture of membranes and preterm delivery (Gonçalves et al., 2002; Romero et al., 2003, 2006). Membranes provide such protection in several ways, the first being structural impermeability to pathogens. Cells in the membranes also express antimicrobial peptides (AMPs) that directly target microorganisms in the hACM or hAF (Zhang et al., 2001; King et al., 2007b; Stock et al., 2007).

Nevertheless, if intra-amniotic infections occur, the fetal membranes and hAF are largely involved in activating and regulating an immune response (Figure 1). This is evidenced by an increased presence of immune cells, upregulated AMP's, cytokines and chemokines, activated pattern recognition receptors that trigger inflammatory signaling pathways, and changes in the extracellular matrix of the hAM (Gillaux et al., 2011; Romero et al., 2016; Myntti et al., 2017; Gomez-Lopez et al., 2019; Bhatti et al., 2020; Galaz et al., 2020; Gomez-Lopez et al., 2020).

\section{ANTIMICROBIAL PEPTIDES IN FETAL MEMBRANES}

Antimicrobial peptides (AMPs) are small proteins produced by some epithelial and immune cells and represent a crucial component of the innate immune system (Frew and Stock, 2011). They exhibit antibacterial, antifungal, antiviral and antiprotozoal activities and also possess anti-inflammatory and immunomodulatory activities, affect cell differentiation, angiogenesis, and wound healing (Mansour et al., 2014; Tribe, 2015; Yarbrough et al., 2015). AMPs play an important role in ensuring a healthy pregnancy and preventing complications (Frew and Stock, 2011). Namely, infections with bacteria, fungi, or viruses during pregnancy are associated with various adverse outcomes, such as miscarriage, eclampsia, premature rupture of membranes, premature delivery, growth restriction, and neonatal morbidity (Frew and Stock, 2011; Mei et al., 2019).

Unsurprisingly, the expression of several AMPs is induced in the case of intra-amniotic infection or inflammation (Figure 1). Among the most prominent AMPs are human $\beta$-defensins (HBD)1-3, which are expressed by multiple cells of hACM and are also found in the hAF (King et al., 2007a,b; Soto et al., 2007; Szukiewicz et al., 2016; Varrey et al., 2018; Para et al., 2020). Human neutrophil peptides (HNP)1-3, which also belong to the $\alpha$ defensin group, are present in the hAF of uncomplicated pregnancies but are more abundant during inflammation (Heine et al., 1998; Espinoza et al., 2003; Yoshio et al., 2003; Akinbi et al., 2004; Buhimschi et al., 2005). Moreover, antiproteases of the WAP (whey acidic protein) four-disulfide core (WFDC) family, elafin and secretory leukocyte peptidase inhibitor (SLPI), were found in hAEC and hCM, and SLPI was present in the hAF as well (Denison et al., 1999; Zhang et al., 2001; Akinbi et al., 2004; King et al., 2007a,b; Klaffenbach et al., 2011). Additionally, in the hAF, cathelicidin family members are responsive to the intra-amniotic infection or inflammation 


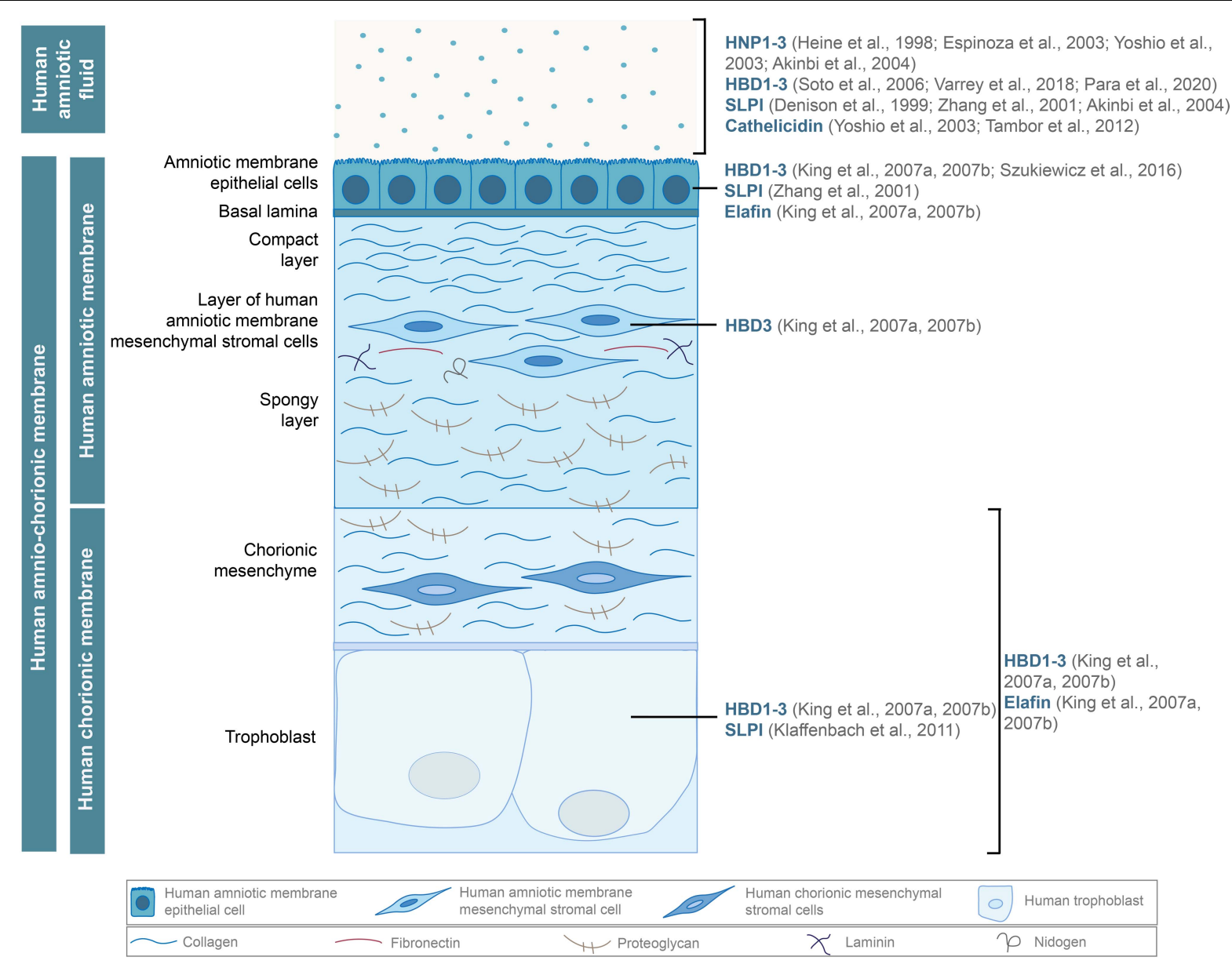

FIGURE 1 | Antimicrobial peptides, such as human $\alpha$ (HNP1-3) and $\beta$-defensins (HBD1-3), cathelicidin, and proteases of the WFDC family (SLPI, elafin), are secreted by the hAM and hCM cells and found in the hAF. Adapted from Cirman et al. (2018).

(Yoshio et al., 2003, 2005; Tambor et al., 2013). AMPs contribute significantly to the antimicrobial effects of fetal membranes and various approaches have been used to characterize and determine the efficiency of antimicrobial activity of fetal membranes and their derivatives against different pathogens.

\section{DIFFERENT APPROACHES FOR STUDYING ANTIMICROBIAL PROPERTIES OF FETAL MEMBRANES}

The use of fetal membranes with the aim of utilizing their medicinal properties was first described by Davis (1910), who used hAM as a skin graft. Although fetal membranes have been used in tissue engineering and regenerative medicine for almost a century, attention was brought to their antimicrobial properties for the first time in 1973 by Robson and Krizek (Robson et al., 1973; Lim, 2017). Over the next decades, researchers evaluated the antimicrobial properties of fetal membranes, using various approaches for the preparation of hACM, hAM and hCM and their derivatives and also several antimicrobial susceptibility testing methods. The studies analyzing antimicrobial properties of fetal membranes and different experimental approaches are summed up in the following subsections and in Tables 1, 2.

Interestingly, to the best of our knowledge, no studies focused solely on the antimicrobial activity of cells isolated from fetal membranes or their conditioned medium. The effect of fetal membranes-derived cells and their derivatives (conditioned medium, extract, supernatant) was only indirectly investigated by comparing the antimicrobial effect of intact and deepithelized hAM (Wang et al., 2012) and analyzing the amount of AMPs present in the extract or conditioned medium derived from fetal membranes (Mao et al., 2017; Tehrani et al., 2017).

\section{The Antimicrobial Activity of hACM Patches}

Robson and Krizek (1973) investigated the effect of the human amnio-chorionic membrane (hACM) on the bacterial population of infected burns. They used hACM immediately after separation or rinsed it in sodium hypochlorite and stored it in saline at $4^{\circ} \mathrm{C}$ until use. On day 0 they inoculated full-thickness burn 
TABLE 1 | Protocols for preparation of hACM, hAM, and hCM and their derivatives, which were used for investigation of antimicrobial activity. There are many variations in protocols for the preparation of fetal membranes to be used as an antimicrobial agent, which underlines the need for protocol standardization before considering clinical use.

\begin{tabular}{|c|c|c|c|}
\hline Perinatal derivative & Preparation protocol & $\begin{array}{l}\text { Use of antibiotics } \\
\text { or other } \\
\text { antimicrobial } \\
\text { agents during } \\
\text { preparation }\end{array}$ & References \\
\hline hACM patches & $\begin{array}{l}\text { hACM was separated from the placenta and rinsed in sterile saline. Patches of hACM } \\
\text { were used immediately after separation or rinsed in } 0.025 \% \text { sodium hypochlorite, } \\
\text { washed in saline, and stored at } 4^{\circ} \mathrm{C} \text { until use. }\end{array}$ & Yes & $\begin{array}{l}\text { Robson and Krizek, } \\
1973\end{array}$ \\
\hline $\begin{array}{l}\text { hACM and hAM } \\
\text { patches }\end{array}$ & $\begin{array}{l}\text { hACM and hAM were separated from the placenta, rinsed in sterile saline, and stored in } \\
\text { sterile isotonic saline solution at } 4^{\circ} \mathrm{C} \text { for up to } 12 \mathrm{~h} \text { before use. }\end{array}$ & No & Talmi et al., 1991 \\
\hline hACM patches & $\begin{array}{l}\text { The hACM was obtained from the BioXclude, Snoasis Medical, Golden, CO, } \\
\text { United States. }\end{array}$ & N/A & Ashraf et al., 2019 \\
\hline hACM patches & $\begin{array}{l}\text { The hACM was obtained from the BioXclude, Snoasis Medical, Golden, CO, } \\
\text { United States. }\end{array}$ & $\mathrm{N} / \mathrm{A}$ & Palanker et al., 2019 \\
\hline hAM and hCM patches & $\begin{array}{l}\text { hAM and hCM were separated from the placenta, rinsed in sterile saline, and used } \\
\text { within } 45 \text { min after the separation. }\end{array}$ & No & $\begin{array}{l}\text { Kjaergaard et al., } \\
2001\end{array}$ \\
\hline hAM patches & $\begin{array}{l}\text { hAM was separated from the placenta and rinsed in sterile PBS. The fresh hAM was } \\
\text { used within the } 4 \mathrm{~h} \text { after the separation. The cryopreserved hAM was stored in sterile } \\
\text { PBS containing } 10 \% \text { dimethylsulphoxide, } 10 \% \text { DMEM/F12, and } 10 \% \text { FBS at }-80^{\circ} \mathrm{C} \text { for } \\
6 \text { months. The freeze-dried hAM was pre-frozen for } 30 \text { min and lyophilized in a } \\
\text { freeze-dryer at }-55^{\circ} \mathrm{C} \text { for } 24 \mathrm{~h} \text { and before use it was rehydrated in PBS for } 2 \mathrm{~h} \text {. }\end{array}$ & No & Tehrani et al., 2013 \\
\hline hAM and hCM patches & $\begin{array}{l}\text { hAM and hCM were separated from the placenta, rinsed in sterile PBS, and cut into } \\
\text { smaller pieces, which were incubated in sterile PBS for a maximum of } 2 \mathrm{~h} \text { at } 4^{\circ} \mathrm{C} \text { before } \\
\text { use. }\end{array}$ & No & $\begin{array}{l}\text { Zare Bidaki et al., } \\
2012\end{array}$ \\
\hline $\begin{array}{l}\text { hAM patches and hAM } \\
\text { homogenate }\end{array}$ & $\begin{array}{l}\text { hAM was separated from the placenta, rinsed in sterile PBS, and cut into smaller } \\
\text { pieces. The patches of fresh hAM (f-hAM) were used within the } 4 \mathrm{~h} \text { after the separation. } \\
\text { The patches of cryopreserved hAM (c-hAM) were stored in sterile PBS at }-80^{\circ} \mathrm{C} \text { for up } \\
\text { to } 10 \text { weeks. The antibiotic-impregnated patches of c-hAM were rinsed with sterile PBS } \\
\text { containing } 50 \mu \mathrm{g} / \mathrm{ml} \text { penicillin, } 50 \mu \mathrm{g} / \mathrm{ml} \text { streptomycin, } 100 \mu \mathrm{g} / \mathrm{ml} \text { neomycin, and } \\
2.5 \mu \mathrm{g} / \mathrm{ml} \text { amphotericin B and then stored in a culture medium supplemented with } \\
\text { gentamicin }(25 \mu \mathrm{g} / \mathrm{ml}) \text {. To prepare f-hAM and c-hAM homogenates, hAM was rinsed } \\
\text { with sterile PBS, cut into pieces and then sterile PBS was added to patches of hAM } \\
\text { (volume ratio } 3 \text { parts of PBS and } 1 \text { part of hAM) and homogenized in a homogenizer } \\
\text { (Russell Hobbs, } 21350-56,300 \mathrm{~W} \text { ) for } 3-4 \text { min. Homogenate was stored at } 4^{\circ} \mathrm{C} \text { for a } \\
\text { maximum of } 6 \text { h before use (f-hAM homogenate) or cryopreserved at }-80 \text { or at }-20^{\circ} \mathrm{C} \\
\text { (c-hAM homogenate) for up to } 10 \text { weeks. }\end{array}$ & $\begin{array}{l}\text { Yes for antibiotic- } \\
\text { impregnated hAM } \\
\text { patches }\end{array}$ & Ramuta et al., 2020 \\
\hline $\begin{array}{l}\text { hAM patches and hAM } \\
\text { homogenate }\end{array}$ & $\begin{array}{l}\text { hAM was separated from the placenta, rinsed in sterile PBS, and cut into smaller pieces. } \\
\text { The patches of f-hAM were used within the } 4 \mathrm{~h} \text { after the separation. The patches of } \\
\mathrm{C}-\mathrm{hAM} \text { were stored in sterile PBS at }-80^{\circ} \mathrm{C} \text { for up to } 1 \text { month. To prepare f-hAM and } \\
\mathrm{C}-\mathrm{hAM} \text { homogenates, hAM was rinsed with sterile PBS, cut into pieces and then sterile } \\
\text { PBS was added to patches of hAM (volume ratio } 3 \text { parts of PBS and } 1 \text { part of hAM) } \\
\text { and homogenized in a homogenizer (Russell Hobbs, } 21350-56,300 \mathrm{~W} \text { ) for } 3-4 \text { min. } \\
\text { Homogenate was stored at } 4^{\circ} \mathrm{C} \text { for a maximum of } 6 \mathrm{~h} \text { before use (f-hAM homogenate) } \\
\text { or cryopreserved at }-80 \text { or at }-20^{\circ} \mathrm{C} \text { (c-hAM homogenate) for up to } 1 \text { month. For } \\
\text { testing the antibacterial activity of hAM homogenate on biomimetic urothelial in vitro } \\
\text { models, the hAM homogenates were prepared in the culture media rather than PBS. }\end{array}$ & No & Ramuta et al., 2021 \\
\hline hAM homogenate & $\begin{array}{l}\text { hAM was separated from the placenta, rinsed in sterile PBS, and cut into smaller } \\
\text { pieces. Sterile PBS was added to pieces of hAM (volume ratio } 3 \text { parts of PBS and } 1 \\
\text { part of hAM) and homogenized in a homogenizer (Russell Hobbs, } 21350-56,300 \mathrm{~W} \text { ) for } \\
\text { 3-4 min. Homogenate was cryopreserved at }-80^{\circ} \mathrm{C} \text { for up to one year. }\end{array}$ & No & Šket et al., 2019 \\
\hline hCVAM patches & $\begin{array}{l}\text { Human term placental tissues were obtained from commercial tissue agencies and } \\
\text { processed by Osiris Therapeutics, Inc. (Columbia, MD, United States) following the } \\
\text { proprietary manufacturing procedure. Namely, the hAM separated from the placenta } \\
\text { within } 36 \text { h of the collection and incubated in the DMEM culture medium containing } \\
\text { gentamicin, vancomycin, and amphotericin B for } 18-48 \text { h at } 37^{\circ} \mathrm{C} \text { and } 5 \% \mathrm{CO}_{2} \text {. } \\
\text { Residual antibiotics were removed by washing the hAM with Dulbecco's PBS and hAM } \\
\text { was cut into pieces. Cryopreservation was performed by freezing hAM in DMSO } \\
\text { containing cryoprotectant at a controlled cooling rate, according to the proprietary } \\
\text { process developed by Osiris Therapeutics, Inc. Before use, hCVAM was thawed at a } \\
\text { room temperature and rinsed in sterile PBS. }\end{array}$ & Yes & Mao et al., 2016 \\
\hline
\end{tabular}


TABLE 1 | Continued

\begin{tabular}{|c|c|c|c|}
\hline Perinatal derivative & Preparation protocol & $\begin{array}{l}\text { Use of antibiotics } \\
\text { or other } \\
\text { antimicrobial } \\
\text { agents during } \\
\text { preparation }\end{array}$ & References \\
\hline $\begin{array}{l}\text { hCVAM conditioned } \\
\text { medium }\end{array}$ & $\begin{array}{l}\text { Human term placental tissues were obtained from commercial tissue agencies and } \\
\text { processed by Osiris Therapeutics, Inc. (Columbia, MD, United States) following the } \\
\text { proprietary manufacturing procedure. Namely, the hAM separated from the placenta } \\
\text { within } 36 \mathrm{~h} \text { of the collection and incubated in the DMEM culture medium containing } \\
\text { gentamicin, vancomycin, and amphotericin B for } 18-48 \mathrm{~h} \text { at } 37^{\circ} \mathrm{C} \text { and } 5 \% \mathrm{CO}_{2} \text {. } \\
\text { Residual antibiotics were removed by washing the hAM with Dulbecco's PBS and hAM } \\
\text { was cut into pieces. Cryopreservation was performed by freezing hAM in DMSO } \\
\text { containing cryoprotectant at a controlled cooling rate, according to the proprietary } \\
\text { process developed by Osiris Therapeutics, Inc. Before use, hCVAM was thawed at } \\
\text { room temperature and rinsed in sterile PBS. To prepare conditioned medium from } \\
\text { hCVAM, the hCVAM was incubated for } 6 / 22 / 24 \mathrm{~h} \text { in DMEM, supplemented with } 10 \% \\
\text { FBS ( } 1 \mathrm{ml} \text { of culture medium per } 4 \mathrm{~cm}^{2} \text { of hCVAM) on a shaker. }\end{array}$ & Yes & Mao et al., 2017 \\
\hline $\begin{array}{l}\text { hCVAM conditioned } \\
\text { medium }\end{array}$ & $\begin{array}{l}\text { Human term placental tissues were obtained from commercial tissue agencies and } \\
\text { processed and Osiris Therapeutics, Inc. (Columbia, MD, United States) following the } \\
\text { proprietary manufacturing procedure. Namely, the hAM separated from the placenta } \\
\text { within } 36 \mathrm{~h} \text { of the collection and incubated in the DMEM culture medium containing } \\
\text { gentamicin, vancomycin, and amphotericin B for } 18-48 \text { h at } 37^{\circ} \mathrm{C} \text { and } 5 \% \mathrm{CO}_{2} \text {. } \\
\text { Residual antibiotics were removed by washing the hAM with Dulbecco's PBS and hAM } \\
\text { was cut into pieces. Cryopreservation was performed by freezing hAM in DMSO } \\
\text { containing cryoprotectant at a controlled cooling rate, according to the proprietary } \\
\text { process developed by Osiris Therapeutics, Inc. Before use, hCVAM was thawed at } \\
\text { room temperature and rinsed in PBS. To prepare conditioned medium from hCVAM, the } \\
\text { hCVAM was incubated for } 4 / 20 / 24 \mathrm{~h} \text { in DMEM, supplemented with } 10 \% \text { FBS ( } 1 \mathrm{ml} \text { of } \\
\text { culture medium per } 4 \mathrm{~cm}^{2} \text { of hCVAM) on a shaker. }\end{array}$ & Yes & Mao et al., 2018 \\
\hline $\begin{array}{l}\text { hAM patches and hAM } \\
\text { supernatant extract }\end{array}$ & $\begin{array}{l}\text { hAM was prepared according to the protocol described by Talmi et al. (1991). To } \\
\text { prepare acellular hAM, the hAM was digested for } 15 \text { min at } 37^{\circ} \mathrm{C} \text { by adding a mixture of } \\
0.25 \% \text { of trypsin and } 0.06 \% \text { EDTA, and then the cells were removed with a cell scraper. } \\
\text { To prepare the hAM homogenate supernatant, the fresh intact hAM was rinsed in } \\
0.01 \mathrm{~mol} / \mathrm{L} \text { PBS at } 4^{\circ} \mathrm{C} \text { for three times. Next, the hAM was cut into fragments and } \\
\text { homogenized after adding } 1: 1 \text { of } 0.01 \mathrm{~mol} / \mathrm{L} \text { PBS. Then the mixture was sonicated, and } \\
\text { PBS was added by } 1: 2 \text { ratio and the solution was centrifuged at } 2000 \mathrm{rpm}, 4^{\circ} \mathrm{C} \text { for } \\
10 \text { min. The supernatant was stored at } 4^{\circ} \mathrm{C} \text { and }-20^{\circ} \mathrm{C} \text { until use. }\end{array}$ & No & Wang et al., 2012 \\
\hline hAM and hCM extracts & $\begin{array}{l}\text { hAM and hCM were separated from the placenta, rinsed in sterile PBS, cut into small } \\
\text { pieces, and frozen using liquid nitrogen. Next, hAM was ground into fine particles using } \\
\text { a mortar and pestle, mixed with PBS ( } 1: 1 \text { ratio, wt/vol), and homogenized on ice for } 1 \mathrm{~h} \text {. } \\
\text { The lysates were then centrifuged twice at } 12,000 \mathrm{rpm} \text { at } 4^{\circ} \mathrm{C} \text { for } 10 \text { min and then the } \\
\text { supernatants were filtered }(0.22 \mu \mathrm{m} \text { pore size) to obtain the hAM extracts. }\end{array}$ & No & Yadav et al., 2017 \\
\hline hAM extract & $\begin{array}{l}\text { hAM was separated from the placenta and rinsed in sterile PBS. To obtain the hAM } \\
\text { extract, hAM was cut into pieces }(1 \times 1 \mathrm{~cm}) \text {, added to an equivalent volume of PBS } \\
\text { and the hAM extract was obtained by sonicating the hAM on ice for } 10 \text { min with } 80 \mathrm{~W} \\
\text { and } 0.5 \mathrm{~s} \text { cycle (Hielscher, Ultrasound Technology, Germany). The mixture was then } \\
\text { centrifuged ( } 800 \mathrm{rpm}, 4 \mathrm{~min}) \text { and the supernatant was stored. }\end{array}$ & No & Tehrani et al., 2017 \\
\hline
\end{tabular}

N/A, information not available.

areas of 50 Sprague-Dawley rats with the overnight culture of Pseudomonas aeruginosa. After 5 days, the 38 rats that survived the wound sepsis underwent surgical removal of the burn eschar. Afterward, the three areas of the burn were treated as follows: one had hACM sutured into the defect; another had a piece of human skin (approximately $0.35 \mathrm{~mm}$ in thickness) sutured into the defect; the third area was left untreated as a control. The positions chosen for each type of treatment were randomized on the various rats. The hACM and skin grafts were replaced by fresh material every $48 \mathrm{~h}$. At the time of each change, tissue biopsies were obtained for quantitative and qualitative bacteriology. Both treatments resulted in a decrease of the bacterial count in virtually all animals, but the degree of decrease was significantly greater when hACMs were applied. They performed another experiment, in which the overnight cultures of $P$. aeruginosa and Escherichia coli were incubated with hACM homogenate or a homogenate of split-thickness human skin. Interestingly, after 18-24 h of incubation, no antibacterial effect of either homogenate was detected. In the last part of this study ten patients with deep partial-thickness or full-thickness burns were treated with topical antibacterial agents and then biological dressings, namely hACM or human skin grafts, were applied. Biological dressings were replaced every $48 \mathrm{~h}$ and were used in full-thickness burns until 
TABLE 2 | The antimicrobial effect of fetal membranes and their derivatives on various microorganisms.

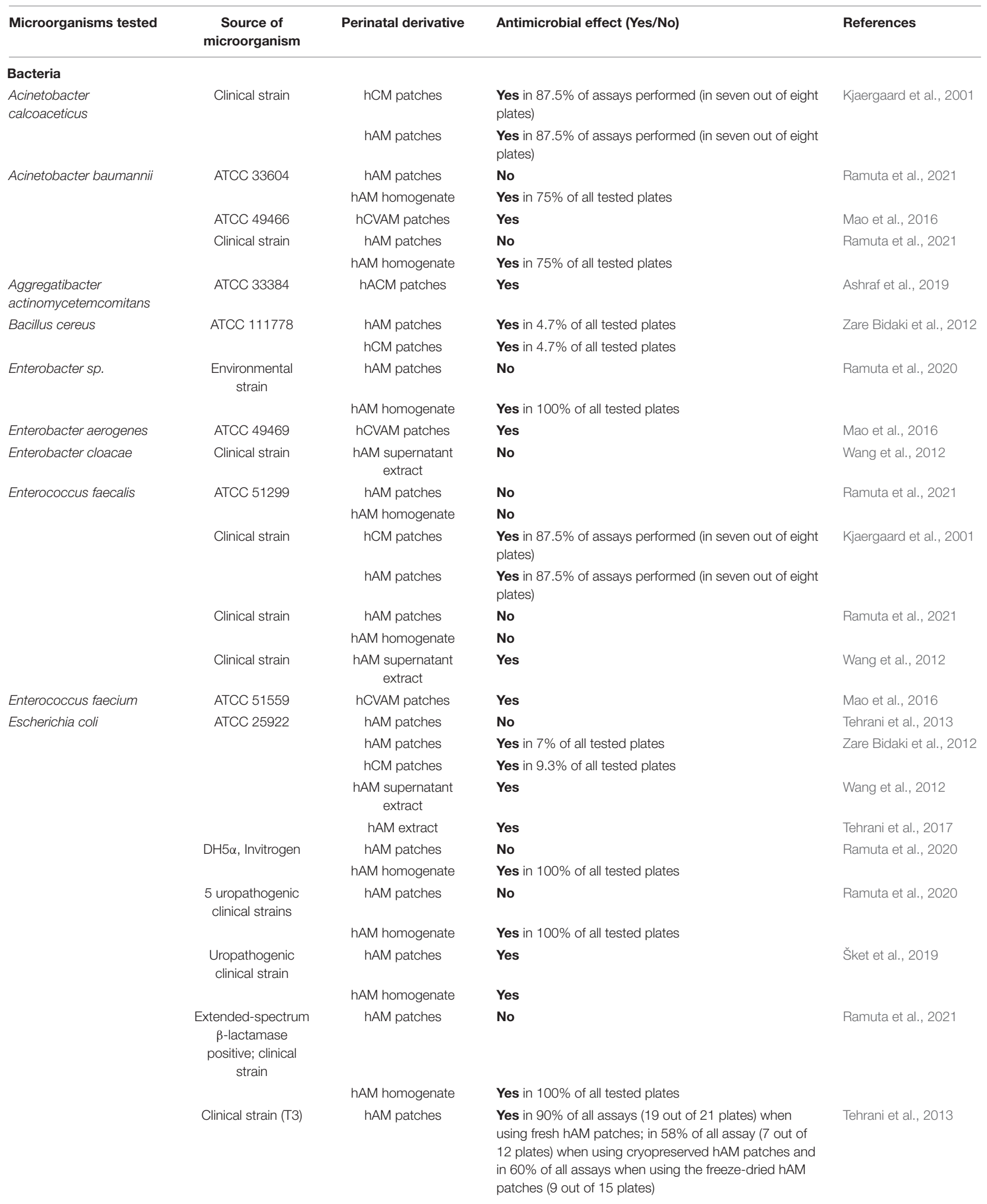


TABLE 2 | Continued

\begin{tabular}{|c|c|c|c|c|}
\hline Microorganisms tested & $\begin{array}{c}\text { Source of } \\
\text { microorganism }\end{array}$ & Perinatal derivative & Antimicrobial effect (Yes/No) & References \\
\hline & & hAM extract & Yes & Tehrani et al., 2017 \\
\hline & Clinical strain & $\begin{array}{l}\text { hAM supernatant } \\
\text { extract }\end{array}$ & No & Wang et al., 2012 \\
\hline & Clinical strain & hCM patches & $\begin{array}{l}\text { Yes in } 87.5 \% \text { of assays performed (in seven out of eight } \\
\text { plates) }\end{array}$ & Kjaergaard et al., 2001 \\
\hline & & hAM patches & $\begin{array}{l}\text { Yes in } 87.5 \% \text { of assays performed (in seven out of eight } \\
\text { plates) }\end{array}$ & \\
\hline \multirow[t]{8}{*}{ Klebsiella pneumoniae } & ATCC 700603 & hCVAM patches & Yes & Mao et al., 2016 \\
\hline & ATCC 700603 & hAM patches & Yes in $4.7 \%$ of all tested plates & Zare Bidaki et al., 2012 \\
\hline & & hCM patches & Yes in $9.3 \%$ of all tested plates & \\
\hline & ATCC 700603 & hAM patches & No & Ramuta et al., 2021 \\
\hline & & hAM homogenate & Yes in $25 \%$ of all tested plates & \\
\hline & $\begin{array}{l}\text { Extended spectrum } \\
\beta \\
\text { lactamase-positive } \\
\text { clinical strain }\end{array}$ & hAM patches & No & Ramuta et al., 2021 \\
\hline & & hAM homogenate & Yes in $25 \%$ of all tested plates & \\
\hline & $\begin{array}{c}\text { Environmental } \\
\text { strain }\end{array}$ & hAM patches & No & Ramuta et al., 2020 \\
\hline \multirow[t]{2}{*}{ Lactobacillus plantarum } & PTCC 1745 & hAM patches & Yes in $4.7 \%$ of all tested plates & Zare Bidaki et al., 2012 \\
\hline & & hCM patches & No & \\
\hline \multirow[t]{2}{*}{ Morganella morganii } & $\begin{array}{l}\text { Environmental } \\
\text { strain }\end{array}$ & hAM patches & No & Ramuta et al., 2020 \\
\hline & & hAM homogenate & Yes in $100 \%$ of all tested plates & \\
\hline \multirow[t]{5}{*}{ Proteus mirabilis } & $\begin{array}{l}\text { Environmental } \\
\text { strain }\end{array}$ & hAM patches & No & Ramuta et al., 2020 \\
\hline & & hAM homogenate & Yes in $100 \%$ of all tested plates & \\
\hline & Clinical strain & $\begin{array}{l}\text { hAM supernatant } \\
\text { extract }\end{array}$ & Yes & Wang et al., 2012 \\
\hline & $N / A$ & hACM patches & Yes & Talmi et al., 1991 \\
\hline & & hAM patches & Yes & \\
\hline \multirow[t]{2}{*}{ Providencia rettgeri } & $\begin{array}{l}\text { Environmental } \\
\text { strain }\end{array}$ & hAM patches & No & Ramuta et al., 2020 \\
\hline & & hAM homogenate & Yes in $100 \%$ of all tested plates & \\
\hline \multirow[t]{3}{*}{ Pseudomonas aeruginosa } & ATCC 15692 & hCVAM patches & Yes & Mao et al., 2016 \\
\hline & & $\begin{array}{l}\text { hCVAM conditioned } \\
\text { medium }\end{array}$ & Yes & Mao et al., 2018 \\
\hline & & $\begin{array}{l}\text { hCVAM conditioned } \\
\text { medium }\end{array}$ & Yes & Mao et al., 2018 \\
\hline
\end{tabular}


TABLE 2 | Continued

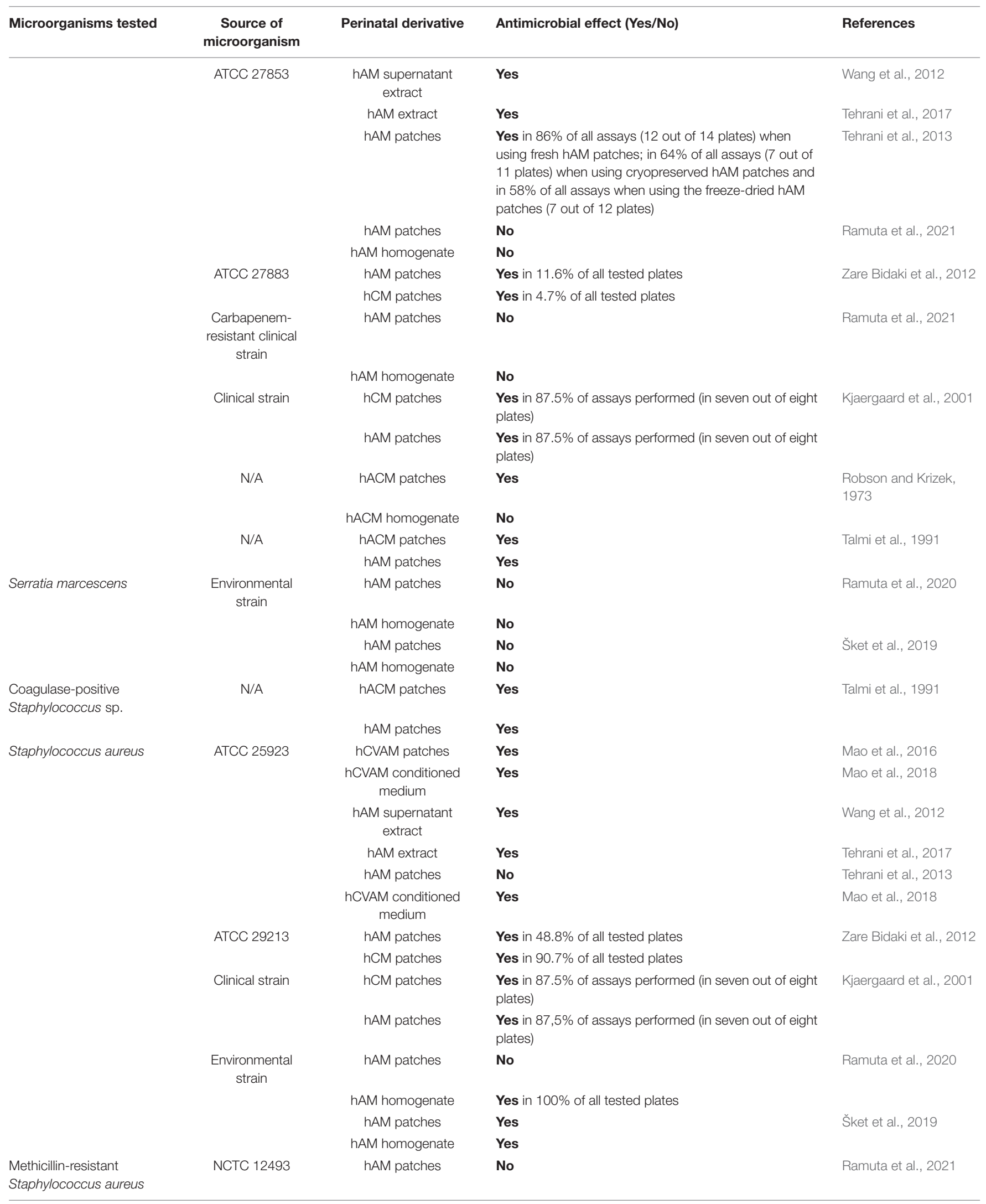


TABLE 2 | Continued

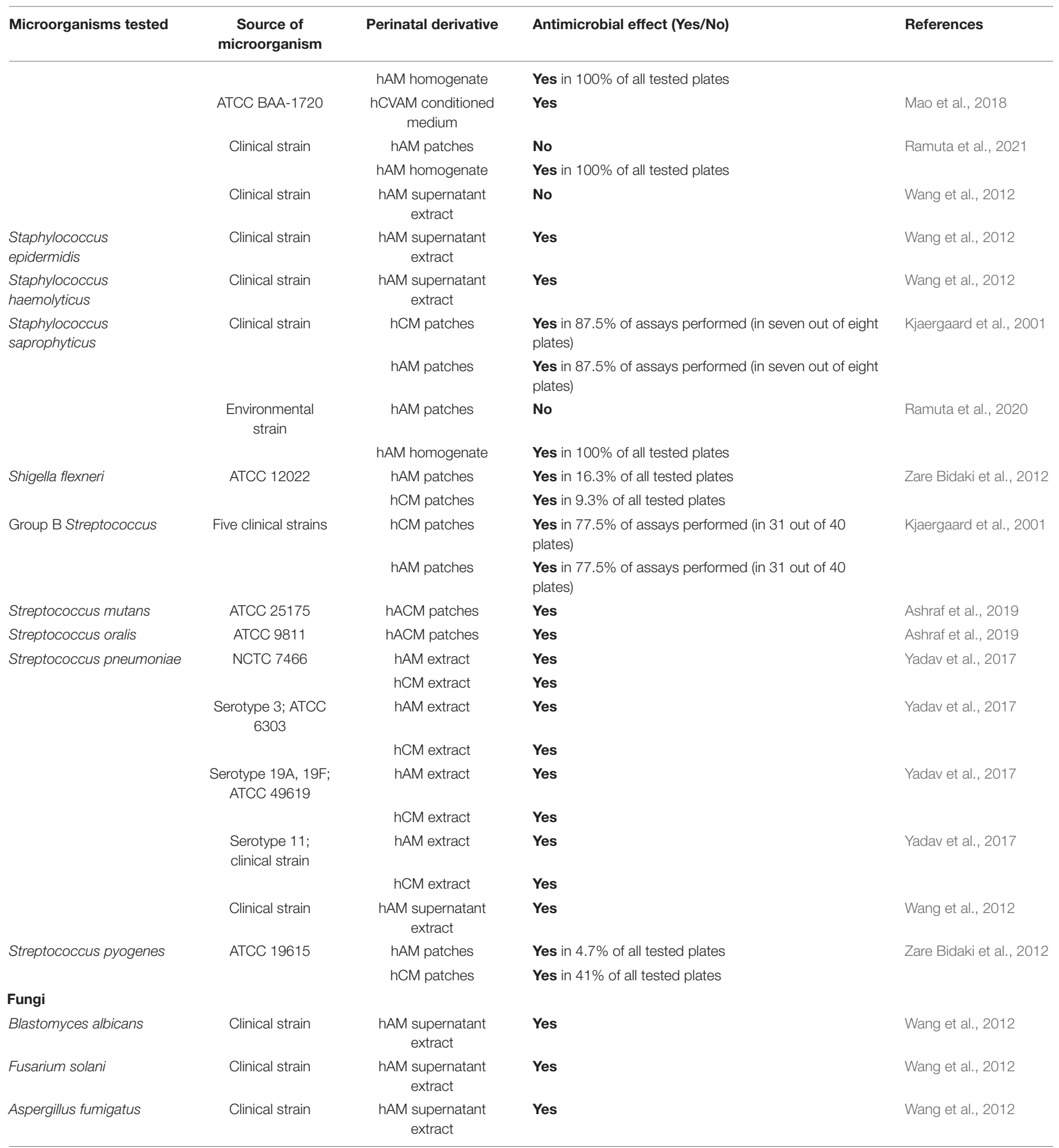

N/A, information not available.

replaced with autografts and in partial-thickness burns until re-epithelization occurred. Application of hACM and human skin grafts resulted in a further decrease of the bacterial count (Robson and Krizek, 1973). Unfortunately, it is not clear which hACM preparation (fresh hACM or hACM that was rinsed in sodium hypochlorite and stored at $4^{\circ} \mathrm{C}$ ) was used for each experiment and this is a large shortcoming of this study since we cannot conclude whether the antimicrobial effect stems from the intrinsic antimicrobial properties of hACM or the remnants of sodium hypochlorite that remained in the hACM 
after rinsing. However, this study served as a meaningful booster for further research.

Talmi et al. (1991) performed a modified disk-diffusion susceptibility test, in which they evaluated the antimicrobial effect of fresh hACM, hAM, and synthetic polyurethane-based membranes on coagulase-positive Staphylococcus sp., E. coli, Klebsiella pneumoniae, $P$. aeruginosa, and Proteus mirabilis. They demonstrated that all membranes inhibited bacterial growth directly under the membranes but there was no inhibition zone, which led researchers to the conclusion that the antimicrobial effect is the result of the adherence of the membranes to the surface (Talmi et al., 1991).

Ashraf et al. (2019) used a commercially available hACM (BioXclude, Snoasis Medical, Golden, CO, United States) and investigated its antimicrobial activity. They inoculated disks of hACM with Aggregatibacter actinomycetemcomitans, Streptococcus mutans, and Streptococcus oralis, collected the samples after 12 and $24 \mathrm{~h}$, and quantified bacterial growth. Their results show that hACM inhibited the growth of all tested bacterial strains at both time points and hACM was as effective as tetracycline $(62 \mu \mathrm{g} / \mathrm{ml})$ that was used as a control (Ashraf et al., 2019). Similarly, Palanker et al. (2019) also used the commercially available hACM (BioXclude), which they inoculated with Streptococcus gordonii. Their results showed that the hACM significantly inhibited bacterial growth at 8,24 , and $48 \mathrm{~h}$ of incubation. As a negative control, they used porcine pericardium collagen membrane, which did not inhibit bacterial growth (Palanker et al., 2019).

\section{The Antimicrobial Activity of the hAM and hCM Patches}

Kjaergaard et al. (2001) investigated the antibacterial activity of fresh hCM and hAM on clinical isolates of hemolytic Streptococcus group A, Staphylococcus aureus, Staphylococcus saprophyticus, Enterococcus faecalis, E. coli, P. aeruginosa, Acinetobacter calcoaceticus, and Lactobacillus sp. They placed fresh hCM and hAM patches, washed only with saline, on bacteria-inoculated agar plates, or suspended them in agar. After $24 \mathrm{~h}$ of incubation, no colonies were found underneath the hCM or hAM patches and there was a narrow inhibition zone $(1 \mathrm{~mm}$ ) around the edge of the membranes in $77.5 \%$ (in 31 out of 40 plates per tested strain) of the group B Streptococcusinoculated agar plates and in $87.5 \%$ (in seven out of eight plates per tested strain) of agar plates inoculated with the rest of aforementioned bacteria. Importantly, after $24 \mathrm{~h}$ of incubation, the researchers removed the hCM and hAM and incubated the plates for additional $24 \mathrm{~h}$ and no reversal of inhibition was observed. Likewise, the fetal membranes immersed in agar also inhibited bacterial growth beneath the membranes. On the other hand, when hCM and hAM were placed in inoculated broth medium, the researchers stated that only hCM showed a marginal inhibition of bacterial growth, while no inhibition was observed with hAM (Kjaergaard et al., 2001).

Wang et al. (2012) investigated the antimicrobial activity of hAM patches on the (1) reference strains of $S$. aureus, P. aeruginosa, and E. coli, (2) clinical strains of Streptococcus pneumoniae, Staphylococcus epidermidis, Staphylococcus haemolyticus, and P. mirabilis, (3) multidrug-resistant clinical strains of E. faecalis, Enterobacter cloacae, E. coli, and methicillin-resistant S. aureus (MRSA) and (4) fungal strains of Blastomyces albicans, Fusarium solani, and Aspergillus fumigatus. They examined the antimicrobial activity of fresh hAM and fresh deepithelized hAM patches and demonstrated that the application of fresh hAM resulted in a significant bacteriostatic ring around the membrane, but the application of the fresh deepithelized hAM patch had not resulted in a bacteriostatic ring, which indicated that antimicrobial molecules are produced by the hAEC (Wang et al., 2012).

Tehrani et al. (2013) compared the antimicrobial efficiency of fresh hAM, cryopreserved hAM, and freeze-dried hAM patches against reference strains of $S$. aureus, $P$. aeruginosa, E. coli, and two clinical strains of $E$. coli using a modified disk diffusion method. When fresh, cryopreserved, and freeze-dried hAM patches were applied to agar plates inoculated with the reference strain of $P$. aeruginosa and both clinical strains of $E$. coli, the bacterial growth was inhibited under all hAM and there was also a narrow inhibition zone (maximum of $5 \mathrm{~mm}$ ) around the hAM. Moreover, the range of the antimicrobial effect varied depending on the preservation method and bacterial strain. On average, the fresh hAM induced antimicrobial effect in $88 \%$ of all plates (43 out of 49 plates) in all susceptible bacterial strains, while the cryopreserved hAM and freeze-dried hAM induced antimicrobial effect in 59\% (20 out of 34 plates) and $62 \%$ of all plates (24 out of 39 plates), respectively. Furthermore, the fresh hAM induced the largest inhibition zones. On the other hand, none of the hAM preparations induced the antimicrobial effect in the reference strains of $S$. aureus and E. coli. The authors also measured the amount of elafin, in the extracts of fresh, cryopreserved, and freeze-dried hAM patches. Their results showed that cryopreservation and freeze-drying significantly decreased the amount of elafin while the antimicrobial effect was still present, which indicates that other antimicrobial molecules and also extracellular matrix may contribute to the antimicrobial effect of hAM (Tehrani et al., 2013). In another study, Tehrani et al. (2017) demonstrated that the orientation of hAM (epithelial or mesenchymal side up) in the modified disc diffusion method does not affect the antimicrobial efficiency of hAM patches. Moreover, they exposed hAM patches to cytokine interleukin $1 \beta$ (IL-1 $\beta$ ) and demonstrated that IL-1 $\beta$ induces a higher level of AMP secretion by the hAM cells, namely elafin, HBD-2, HBD-3, and cathelicidin LL-37 (Tehrani et al., 2017).

Zare Bidaki et al. (2012) placed fresh patches of hAM and hCM on agar plates inoculated with the following bacterial strains: E. coli, Bacillus cereus, K. pneumoniae, Streptococcus pyogenes, S. aureus, Shigella flexneri, and Lactobacillus plantarum. Their results showed that the application of hAM patches resulted in an inhibition zone in 5\% (K. pneumoniae, S. pyogenes, L. plantarum) to $49 \%$ (S. aureus) of tested plates, while the application of hCM patches resulted in an inhibition zone in 5\% (S. pyogenes, $B$. cereus) to $91 \%$ (S. aureus) of tested plates, but did not cause an inhibition zone in L. plantarum (Zare Bidaki et al., 2012).

The antimicrobial activity of hAM patches was also investigated by our research group. We prepared fresh and 
cryopreserved patches of hAM and tested their antimicrobial activity against 14 strains of most common uropathogenic bacteria (5 clinical strains of uropathogenic E. coli (UPEC) and 1 reference or environmental strain of S. aureus, E. coli, S. saprophyticus, Morganella morganii, Providencia rettgeri, K. pneumoniae, P. mirabilis, Serratia marcescens, Enterobacter sp.) (Ramuta et al., 2020) and 11 strains of multidrug-resistant bacteria associated with urinary tract infections (reference and clinical strains of MRSA, extended-spectrum $\beta$-lactamases (ESBL) producing E. coli and K. pneumoniae, vancomycinresistant Enterococci, carbapenem-resistant Acinetobacter baumannii, and P. aeruginosa) (Ramuta et al., 2021). The fresh and cryopreserved hAM patches were embedded into Muller-Hinton soft agar inoculated with the aforementioned strains and after $24 \mathrm{~h}$ of incubation, the antimicrobial effect was evaluated. Interestingly, the application of neither fresh nor cryopreserved patches of hAM resulted in the antimicrobial effect in any of the tested strains. Therefore, we further evaluated the antimicrobial activity of hAM that was prepared and stored according to the standard procedure for use of hAM in ophthalmology (Jirsova and Jones, 2017). Specifically, hAM was during preparation briefly washed with antibiotics and antimycotics $(50 \mu \mathrm{g} / \mathrm{ml}$ penicillin, $50 \mu \mathrm{g} / \mathrm{ml}$ streptomycin, $100 \mu \mathrm{g} / \mathrm{ml}$ neomycin, $2.5 \mu \mathrm{g} / \mathrm{ml}$ amphotericin B) and then stored in a culture medium supplemented with gentamicin $(25 \mu \mathrm{g} / \mathrm{ml})$. So prepared membrane was applied to two clinical strains of UPEC, one strain of $S$. marcescens, and two gentamicin-resistant UPEC strains. The antimicrobial effect was observed with all tested wild-type strains, but no antimicrobial effect was observed in the case of gentamicin-resistant UPEC strains. We demonstrated that the observed antimicrobial effect was due to the presence of gentamicin in the hAM patches. Further, experiments with gentamicin-sensitive UPEC strains revealed that even extensive rinsing of hAM patches in PBS only decreased the concentration of the antibiotics in the hAM patches, but did not completely remove them. Therefore, we suggested the high retention of antibiotics in hAM patches could be attributed to its ultrastructure, as the unique structure and composition of the hAM stroma might enable entrapment of antibiotics inside the extracellular matrix. Hence, hAM patches have great potential to be used as drug delivery tools (Ramuta et al., 2020).

Mao et al. (2016) used patches of commercially available so-called human cryopreserved viable amniotic membrane (hCVAM; Osiris Therapeutics Inc., Columbia, MD, United States; Table 1) and placed them on the agar plates, which were then inoculated with Enterococcus faecium, S. aureus, K. pneumoniae, A. baumannii, P. aeruginosa, and Enterobacter aerogenes. After $18 \mathrm{~h}$ bacteria were eluted from samples and quantified. Next, they incubated patches of hCVAM in $1 \mathrm{ml}$ of culture medium containing bacteria for $24 \mathrm{~h}$ and then quantified the number of bacteria. Using both methods they demonstrated that hCVAM patches had an antibacterial effect on all tested strains (Mao et al., 2016).

In the next study, Mao et al. (2017) prepared the conditioned medium by incubating the hCVAM patches in culture medium for 6,22 , and $24 \mathrm{~h}$. They showed that the conditioned medium had an antimicrobial effect on $P$. aeruginosa, $S$. aureus, and MRSA. In addition, they also showed that the antimicrobial activity was mediated via the secretion of soluble factors by viable cells in hCVAM, as the antimicrobial effect in the conditioned medium prepared from the air-dried devitalized membrane was significantly lower. After analyzing the hCVAM conditioned medium obtained after 6 and $22 \mathrm{~h}$ of incubation, they showed that the accumulation of antimicrobial factors in the conditioned medium is time-dependent as the conditioned medium obtained after $22 \mathrm{~h}$ of incubation had the largest antimicrobial effect and the largest expression of HBD-2 and HBD-3, histone H2B and SLPI. Moreover, by employing immunoprecipitation they removed HBD-2 and HBD-3 from the conditioned medium and demonstrated that HBD-2 and HBD-3depleted hCVAM conditioned medium has reduced antibacterial activity (Mao et al., 2017).

The same research group investigated also the effect of hCVAM-derived conditioned medium on the $S$. aureus and $P$. aeruginosa biofilm formation. They demonstrated that the formation of biofilm was reduced in the presence of the hCVAMderived conditioned medium. Moreover, they confirmed this result with the ex vivo experiment. Namely, they incubated sterile porcine dermal tissue pieces in hCVAM-conditioned medium or in assay medium (control) for $4 \mathrm{~h}$ at room temperature with gentle shaking. Then they inoculated the surface of porcine dermal tissue saturated with hCVAM- conditioned medium or the assay medium with $P$. aeruginosa and performed a quantitative assessment of the biofilm after $48 \mathrm{~h}$ of incubation. They showed that the biofilm formation on porcine dermal tissues saturated with the hCVAM-conditioned medium was reduced by $97 \%$ in comparison to the biofilm formation on the dermal tissues saturated with assay medium. Interestingly, no significant inhibition of $S$. aureus or MRSA biofilm formation was observed in dermal tissues treated with hCVAM-derived conditioned medium (Mao et al., 2018).

The studies by Mao et al. (2016, 2017, 2018) importantly contribute to basic knowledge regarding the antimicrobial activity of hCVAM patches and conditioned medium against several clinically important pathogens. However, it is important to note that the procedure for preparation of hCVAM includes incubation in a culture medium supplemented with antibiotics and antimycotics (Duan-Arnold et al., 2015) and since the authors did not investigate whether there were any remnants of the antibiotics and antimycotics in the hCVAM after rinsing, it is impossible to know whether the antimicrobial activity of hCVAM can be solely attributed to the hAM-derived AMPs.

\section{The Antimicrobial Activity of the hAM Homogenate}

Homogenate is a mixture of extracellular matrix and cells that has been obtained by mechanical disruption. Our research group prepared fresh (f-hAM) and cryopreserved hAM homogenate (c-hAM) and evaluated their antimicrobial activity against 14 strains of the most common uropathogenic bacteria (Ramuta et al., 2020) and 11 strains of multidrug-resistant bacteria associated with urinary tract infections (Ramuta et al., 2021). 
Using the antimicrobial efficiency assay with f-hAM and c-hAM homogenates on agar plates, we showed that hAM homogenates caused an inhibition zone in all performed tests in 16 out of 25 tested strains (five clinical strains of UPEC, a clinical strain of $\beta$ lactamase-producing E. coli, laboratory strain of E. coli $\mathrm{DH} 5 \alpha$, reference and clinical strain of methicillin-resistant $S$. aureus, environmental strains of $S$. saprophyticus, $S$. aureus, $M$. morganii, $P$. rettgeri, K. pneumoniae, $P$. mirabilis, Enterobacter spp.), while in two strains they caused an inhibition zone in $25 \%$ of performed tests (reference and clinical strains of $\beta$ lactamase-producing K. pneumoniae), and in two strains they caused an inhibition zone in $75 \%$ of performed tests (reference and clinical strains of A. baumannii). Moreover, in five strains the f-hAM and c-hAM homogenates did not cause an inhibition zone in any of the performed tests (reference and clinical strains of $P$. aeruginosa and E. faecalis and environmental strain of S. marcescens). Next, we demonstrated that the manner of preparation and storage of hAM homogenate affects the range of its antimicrobial activity. Namely, the application of f-hAM homogenates resulted in the largest diameter of the inhibition zone, followed by (1) c-hAM homogenates that were stored for 10 weeks at $-20^{\circ} \mathrm{C}$, (2) c-hAM homogenates that were stored for 1 week at $-80^{\circ} \mathrm{C}$ and (3) c-hAM homogenates that were stored for 10 weeks at $-80^{\circ} \mathrm{C}$. Application of larger volumes $(10 \mu \mathrm{l})$ of hAM homogenates also resulted in a larger inhibition zone than an application of smaller volumes $(5 \mu \mathrm{l})$ of hAM homogenates. In another study (Šket et al., 2019) we investigated the antimicrobial activity of c-hAM homogenate in bacteria-inoculated liquid culture medium and we demonstrated that c-hAM homogenate, when twofold diluted had a bacteriostatic effect on UPEC and S. aureus and when it was diluted fourfold or eightfold had a bactericidal effect $S$. aureus strain. Moreover, in accordance with our experiments on agar plates, the c-hAM homogenate had no antimicrobial effect on S. marcescens in a liquid culture medium.

To test whether the c-hAM homogenate causes such robust antimicrobial effect also in a more complex microenvironment, we evaluated its antimicrobial activity in the MRSA-infected biomimetic in vitro models of normal and cancerous urinary bladder urothelia. We demonstrated that even a short-term incubation ( $3 \mathrm{~h}$ ) in hAM homogenate significantly decreased the number of bacteria, but it did not affect the viability, number, and ultrastructure of urothelial cells (Ramuta et al., 2021).

\section{The Antimicrobial Activity of the hAM and hCM Supernatants and/or Extracts}

Wang et al. (2012) investigated the antimicrobial activity of human amniotic homogenate supernatant (HAHS). To prepare HAHS, fragments of hAM have been sonicated, centrifuged and then the supernatant was obtained. HAHS were tested on the (1) reference strains of $S$. aureus, $P$. aeruginosa, and E. coli, (2) clinical strains of S. pneumoniae, S. epidermidis, $S$. haemolyticus and P. mirabilis, (3) multidrug-resistant clinical strains of E. faecalis, E. cloacae, E. coli and MRSA and (4) fungal strains of B. albicans, F. solani, and A. fumigatus. They reported that HAHS induced antimicrobial effect in all three reference strains, S. epidermidis, P. mirabilis, S. pneumoniae,
E. faecalis, F. solani, B. albicans, and A. fumigatus, but did not induce an antimicrobial effect in multidrug-resistant E. cloacae, E. coli and MRSA. Moreover, they also demonstrated the stable antimicrobial characteristics of HAHS, since changes in $\mathrm{pH}(\mathrm{pH}$ values $5.0,6.0,7.0,8.0,9.0)$, temperature $\left(-20,4,20,60^{\circ} \mathrm{C}\right)$ and storage time $\left(1,3,7,14,28,56\right.$ days at $\left.4{ }^{\circ} \mathrm{C}\right)$ of HAHS did not significantly alter the antimicrobial efficiency of HAHS (Wang et al., 2012).

Yadav et al. (2017) prepared hAM and hCM extracts by grounding the frozen fragments of hAM and hCM using a mortar and pestle, mixing the particles with PBS, centrifuging the mixture and obtaining the supernatant that was filter sterilized. The so-called hAM and hCM extracts were used for evaluation of their antibacterial and antibiofilm activities against Streptococcus pneumoniae on an in vitro biofilm model and in vivo otitis media rat model. They demonstrated that the hAM and hCM extracts inhibited the growth of S. pneumoniae in planktonic form and decreased their microbial biomass in biofilms. Moreover, they also showed that biofilms that grew in the hAM and hCM extract were thin, scattered, and unorganized, and importantly, the hAM and hCM extracts strongly reduced the microbial biomass in the pre-established pneumococci biofilms and had a bactericidal effect. They also combined the hAM and hCM extracts with penicillin and streptomycin and showed that the hAM and hCM extracts together with antibiotics had a synergistic effect against $S$. pneumoniae. In the in vivo model, the hAM extract significantly reduced bacterial colonization in the rat middle ear. The authors also performed proteomics analysis and showed that the hAM and hCM extracts contain ribonucleases (ribonuclease T2, ribonuclease $\mathrm{K} 6$, ribonuclease 7 , ribonuclease $\mathrm{H} 2$, ribonuclease pancreatic, ribonuclease 5) and antimicrobial peptides lactoferricin, lysozyme, dermcidin, granulysin, the proteins S100-A9 and S100-A8, $\beta-2$ microglobulin, antileukoproteinase, histones H2B type 1-D, type 1-O, HRA-V and H1-4 and HBD-3 (Yadav et al., 2017).

The antimicrobial activity of hAM extract was investigated also by Tehrani et al. (2017). Their results showed that the application of hAM extract resulted in a decrease in the number of colonies of $P$. aeruginosa, E. coli, and S. aureus (Tehrani et al., 2017).

\section{TRANSLATION OF FETAL MEMBRANES FROM PRECLINICAL TO CLINICAL USE: WHAT REMAINS TO BE DONE?}

Studies have shown that fetal membranes and their derivatives have broad-spectrum antimicrobial activity against a plethora of Gram-positive and Gram-negative bacteria and even some fungi. While these results are very promising, especially as they demonstrate that even some of the multidrug-resistant bacteria are susceptible to the antimicrobial activity of fetal membranes, there are several considerations to be taken into account when planning future studies and eventual translation from bench to bedside. 


\section{Standardization of Sample Preparation}

An overview of studies investigating the antimicrobial activity of fetal membranes and their derivatives showed that in numerous cases various authors present conflicting results using the same bacterial species or even the same bacterial strains. That illustrates the need for standardization of hACM, hAM, and hCM preparation as we can conclude from these studies that even minor differences in protocols account for diverse outcomes (Tables 1, 2). Therefore, to enable comparison of results among various studies, it is of the utmost importance that future studies report on the protocols for preparation and storage meticulously, including the information regarding rinsing (which buffer was used, how many times the fetal membrane was washed), storage times and temperatures, centrifugation specifications, sonication specifications, buffer and culture medium composition, etc. Moreover, going forward, research on antimicrobial properties of fetal membranes and their derivatives must be performed using only those that did not come into contact with antibiotics during preparation and storage. This is very important due to hAM's capability for drug retention (Kim et al., 2001; Mencucci et al., 2006; Resch et al., 2011; Yelchuri et al., 2017; Sara et al., 2019; Ramuta et al., 2020) and it is otherwise impossible to conclude how much of the antimicrobial effect can be attributed to fetal membranes' innate AMPs. Additionally, to be able to compare the antimicrobial effect of various hACM, hAM, and hCM-derived preparations, it will also be necessary to employ the same antimicrobial susceptibility testing methods. It will also be necessary to establish clinical laboratory standards for susceptibility testing of infectious agents to fetal membranederived preparations, similar to the Clinical \& Laboratory Standards for antibiotics (Humphries et al., 2018). That would allow infectious agents to be characterized as "susceptible," "intermediate" or "resistant" to various hACM, hAM, and hCMderived preparations.

\section{Is Antimicrobial Activity of hACM Superior to hAM or hCM Alone?}

If we wish to progress from bench to bedside, future studies will have to ascertain which fetal membrane-derived preparations at which concentrations provide the best clinical outcome. The review of the current literature does not offer a definitive answer which fetal membrane or fetal membrane-derived preparation provides the best antimicrobial effect. Namely, the hACM, hAM, and hCM have all been shown to possess antimicrobial properties, but to the best of our knowledge, no study compared the antimicrobial effect of these preparations on the same bacterial strains in the same experimental setting, it is therefore impossible to conclude which preparation is superior. However, until now, most studies investigating the antimicrobial properties of fetal membranes have been performed using hAM and since it has many properties that are beneficial in regenerative medicine, such as immunomodulatory properties (Magatti et al., 2016, 2018; Wassmer and Berishvili, 2020), promotion of epithelization and decrease of scarring (Koizumi et al., 2000; Gicquel et al., 2009; SantAnna et al., 2016), the translation from pre-clinic to clinic might be most swift for hAM. However, further research projects, which would address antimicrobial activity of hACM and hCM in the same experimental settings as were done for hAM, are highly recommended.

\section{The Need for More in vivo Studies}

The majority of what we know regarding the antimicrobial properties of hACM, hCM, and hAM comes from in vitro studies. While these are of immense importance as they significantly contribute to our understanding of the mechanism of antimicrobial activity of fetal membranes, and their derivatives, there is a great deficiency of the in vivo studies, especially on large animals, which would allow us to evaluate the antimicrobial properties in a more complex (micro)environment. Moreover, the in vivo studies will also provide much-needed information regarding the safety of hACM, hCM, hAM, and their derivatives.

\section{Donor Selection}

Future research should also focus on donor selection. Currently, most fetal membranes used for research are obtained from healthy donors that tested negative for HIV, hepatitis B, and syphilis and underwent a Cesarean section at a gestation age of 38-40 weeks. To reach optimal results it would be necessary to evaluate how the age and the lifestyle of the donor, gestation age, and manner of delivery (vaginal vs. Cesarean) affect the AMP production and secretion.

\section{The Possibility of Antimicrobial Resistance}

Another aspect to consider when evaluating the potential of fetal membranes and their derivatives to be used as antimicrobial agents is the possibility of microbes developing resistance to antimicrobial molecules derived from fetal membranes. Therefore, future studies should focus also on assessing the risk of development and spread of microbial resistance to fetal membrane-derived antimicrobials, since that would pose an immense threat to the health of pregnant women and their developing children worldwide.

\section{CONCLUSION}

To conclude, the use of fetal membranes has many advantages, since they provide a valuable source of cells and extracellular matrix with regenerative properties, they are immune-privileged tissue and importantly, their use is ethically acceptable (Lim, 2017). On the other hand, the use of fetal membranes comes with some challenges, such as donor variability, lack of standardized protocols for preparation, and limited shelf life. However, in the last decades, the number of studies investigating the properties and potential clinical use of fetal membranes is increasing, which led to a broadening of basic knowledge in the field of fetal membranes. Moreover, future studies will provide additional insight that will enable us to take advantage of various beneficial properties of fetal membranes and overcome the current challenges. 


\section{AUTHOR CONTRIBUTIONS}

TŽR and MEK: conceptualization. TŽR: visualization. TŽR and TŠ: writing - original draft preparation. TŽR, TŠ, MSE, and MEK: writing - review and editing. All authors: read and approved the final version of the manuscript.

\section{FUNDING}

This research was funded by the Slovenian Research Agency (project J7-2594, and research core funding nos.

\section{REFERENCES}

Akinbi, H. T., Narendran, V., Pass, A. K., Markart, P., and Hoath, S. B. (2004). Host defense proteins in vernix caseosa and amniotic fluid. Am. J. Obst. Gynecol. 191, 2090-2096. doi: 10.1016/j.ajog.2004.05.002

Anderson, D. F., Jonker, S. S., Louey, S., Cheung, C. Y., and Brace, R. A. (2013). Regulation of intramembranous absorption and amniotic fluid volume by constituents in fetal sheep urine. Am. J. Physiol. Regul. Integr. Comp. Physiol. 305, R506-R511.

Ashraf, H., Font, K., Powell, C., and Schurr, M. (2019). Antimicrobial activity of an amnion-chorion membrane to oral microbes. Int. J. Dent. 2019: 1269534.

Bhatti, G., Romero, R., Rice, G. E., Fitzgerald, W., Pacora, P., Gomez-Lopez, N., et al. (2020). Compartmentalized profiling of amniotic fluid cytokines in women with preterm labor. Plos One 15:e0227881. doi: 10.1371/journal.pone.022 7881

Brace, R. A., Cheung, C. Y., and Anderson, D. F. (2013). Inhibitor of intramembranous absorption in ovine amniotic fluid. Am. J. Physiol. Regul. Integr. Comp. Physiol. 306, R185-R189.

Brace, R. A., Cheung, C. Y., and Anderson, D. F. (2018). Regulation of amniotic fluid volume: insights derived from amniotic fluid volume function curves. Am. J. Physiol. Regul. Integr. Comp. Physiol. 315, R777-R789.

Brace, R. A., and Wolf, E. J. (1989). Normal amniotic fluid volume changes throughout pregnancy. Am. J. Obst. Gynecol. 161, 382-388. doi: 10.1016/00029378(89)90527-9

Bryant-Greenwood, G. D. (1998). The extracellular matrix of the human fetal membranes: structure and function. Placenta 19, 1-11. doi: 10.1016/s01434004(98)90092-3

Buhimschi, I. A., Christner, R., and Buhimschi, C. S. (2005). Proteomic biomarker analysis of amniotic fluid for identification of intra-amniotic inflammation. BJOG 112, 173-181. doi: 10.1111/j.1471-0528.2004.00340.x

Castellanos, G., Bernabé-García, Á, Moraleda, J. M., and Nicolás, F. J. (2017). Amniotic membrane application for the healing of chronic wounds and ulcers. Placenta 59, 146-153. doi: 10.1016/j.placenta.2017.04.005

Cirman, T., Beltram, M., Schollmayer, P., Rožman, P., and Kreft, M. E. (2014). Amniotic membrane properties and current practice of amniotic membrane use in ophthalmology in Slovenia. Cell Tissue Bank 15, 177-192. doi: 10.1007/ s10561-013-9417-6

Cirman, T., Ramuta, T., Lužnik, Z., Hawlina, M., Schollmayer, P., Smrke, D., et al. (2018). The amniotic membrane as a biological scaffold, its preparation and use in regenerative medicine in Slovenia. Zdravniski Vestnik 87:17.

Davis, J. W. (1910). Skin transplantation with a review of 550 cases at the Johns Hopkins Hospital. Johns Hopkins Med. J. 15:87.

Denison, F. C., Kelly, R. W., Calder, A. A., and Riley, S. C. (1999). Secretory leukocyte protease inhibitor concentration increases in amniotic fluid with the onset of labour in women: characterization of sites of release within the uterus. J. Endocrinol. 161, 299-306. doi: 10.1677/joe.0.1610299

Deptuła, M., Zieliński, J., Wardowska, A., and Pikuła, M. (2019). Wound healing complications in oncological patients: perspectives for cellular therapy. Postepy Dermatol. Alergol. 36, 139-146. doi: 10.5114/ada.2018.72585

Duan-Arnold, Y., Gyurdieva, A., Johnson, A., Uveges, T. E., Jacobstein, D. A., and Danilkovitch, A. (2015). Retention of endogenous viable
P3-0108, P1-0198) and the MRIC UL IP-0510 Infrastructure program.

\section{ACKNOWLEDGMENTS}

This work contributes to the COST Action CA17116 International Network for Translating Research on Perinatal Derivatives into Therapeutic Approaches (SPRINT), supported by COST (European Cooperation in Science and Technology).

cells enhances the anti-inflammatory activity of cryopreserved amnion. Adv. Wound Care (New Rochelle) 4, 523-533. doi: 10.1089/wound.2015. 0636

Espinoza, J., Chaiworapongsa, T., Romero, R., Edwin, S., Rathnasabapathy, C., Gomez, R., et al. (2003). Antimicrobial peptides in amniotic fluid: defensins, calprotectin and bacterial/permeability-increasing protein in patients with microbial invasion of the amniotic cavity, intra-amniotic inflammation, preterm labor and premature rupture of membranes. J. Matern. Fetal. Neonatal. Med. 13, 2-21. doi: 10.1080/jmf.13.1.2.21

Farhadihosseinabadi, B., Farahani, M., Tayebi, T., Jafari, A., Biniazan, F., Modaresifar, K., et al. (2018). Amniotic membrane and its epithelial and mesenchymal stem cells as an appropriate source for skin tissue engineering and regenerative medicine. Artif. Cells Nanomed. Biotechnol. 46, 431-440. doi: 10.1080/21691401.2018.1458730

Frew, L., and Stock, S. J. (2011). Antimicrobial peptides and pregnancy. Reproduction 141, 725-735. doi: 10.1530/rep-10-0537

Galaz, J., Romero, R., Slutsky, R., Xu, Y., Motomura, K., Para, R., et al. (2020). Cellular immune responses in amniotic fluid of women with preterm prelabor rupture of membranes. J. Perinat. Med. 48, 222-233. doi: 10.1515/jpm-20190395

Gicquel, J. J., Dua, H. S., Brodie, A., Mohammed, I., Suleman, H., Lazutina, E., et al. (2009). Epidermal growth factor variations in amniotic membrane used for ex vivo tissue constructs. Tissue Eng. Part A 15, 1919-1927. doi: 10.1089/ ten.tea.2008.0432

Gillaux, C., Méhats, C., Vaiman, D., Cabrol, D., and Breuiller-Fouché, M. (2011). Functional screening of TLRs in human amniotic epithelial cells. J. Immunol. 187, 2766-2774. doi: 10.4049/jimmunol. 1100217

Gomez-Lopez, N., Romero, R., Galaz, J., Xu, Y., Panaitescu, B., Slutsky, R., et al. (2020). Cellular immune responses in amniotic fluid of women with preterm labor and intra-amniotic infection or intra-amniotic inflammation. Am. J. Reprod. Immunol. 82:e13171.

Gomez-Lopez, N., Romero, R., Maymon, E., Kusanovic, J. P., Panaitescu, B., Miller, D., et al. (2019). Clinical chorioamnionitis at term IX: in vivo evidence of intra-amniotic inflammasome activation. J. Perinat. Med. 47, 276-287. doi: 10.1515/jpm-2018-0271

Gonçalves, L. F., Chaiworapongsa, T., and Romero, R. (2002). Intrauterine infection and prematurity. Ment. Retard. Dev. Disabil. Res. Rev. 8, 3-13. doi: 10.1002/mrdd.10008

Guo, S., and Dipietro, L. A. (2010). Factors affecting wound healing. J. Dent. Res. 89, 219-229.

Heine, R. P., Wiesenfeld, H., Mortimer, L., and Greig, P. C. (1998). Amniotic fluid defensins: potential markers of subclinical intrauterine infection. Clin. Infect. Dis. 27, 513-518. doi: 10.1086/514691

Humphries, R. M., Ambler, J., Mitchell, S. L., Castanheira, M., Dingle, T., Hindler, J. A., et al. (2018). CLSI methods development and standardization working group best practices for evaluation of antimicrobial susceptibility tests. J. Clin. Microbiol. 56, e1917-e1934.

Ikada, Y. (2006). Challenges in tissue engineering. J. R. Soc. Interface 3, 589-601.

Jirsova, K., and Jones, G. L. (2017). Amniotic membrane in ophthalmology: properties, preparation, storage and indications for grafting-a review. Cell Tissue Bank 18:12. 
Joyce, E. M., Moore, J. J., and Sacks, M. S. (2009). Biomechanics of the fetal membrane prior to mechanical failure: review and implications. Eur. J. Obst. Gynecol. Reprod. Biol. 144, S121-S127.

Kim, J. S., Kim, J. C., Hahn, T. W., and Park, W. C. (2001). Amniotic membrane transplantation in infectious corneal ulcer. Cornea 20, 720-726. doi: 10.1097/ 00003226-200110000-00010

King, A. E., Kelly, R. W., Sallenave, J. M., Bocking, A. D., and Challis, J. R. (2007a). Innate immune defences in the human uterus during pregnancy. Placenta 28, 1099-1106. doi: 10.1016/j.placenta.2007.06.002

King, A. E., Paltoo, A., Kelly, R. W., Sallenave, J. M., Bocking, A. D., and Challis, J. R. (2007b). Expression of natural antimicrobials by human placenta and fetal membranes. Placenta 28, 161-169. doi: 10.1016/j.placenta.2006. 01.006

Kjaergaard, N., Hein, M., Hyttel, L., Helmig, R. B., Schonheyder, H. C., Uldbjerg, N., et al. (2001). Antibacterial properties of human amnion and chorion in vitro. Eur. J. Obstet. Gynecol. Reprod Biol. 94, 224-229. doi: 10.1016/s0301-2115(00) 00345-6

Klaffenbach, D., Friedrich, D., Strick, R., Strissel, P. L., Beckmann, M. W., Rascher, W., et al. (2011). Contribution of different placental cells to the expression and stimulation of antimicrobial proteins (AMPs). Placenta 32, 830-837. doi: 10.1016/j.placenta.2011.08.004

Kogan, S., Sood, A., and Granick, M. S. (2018). Amniotic membrane adjuncts and clinical applications in wound healing: a review of the literature. Wounds 30, $168-173$.

Koizumi, N. J., Inatomi, T. J., Sotozono, C. J., Fullwood, N. J., Quantock, A. J., and Kinoshita, S. (2000). Growth factor mRNA and protein in preserved human amniotic membrane. Curr. Eye Res. 20, 173-177. doi: 10.1076/02713683(200003)2031-9ft173

Kuijer, R., Jansen, E. J., Emans, P. J., Bulstra, S. K., Riesle, J., Pieper, J., et al. (2007). Assessing infection risk in implanted tissue-engineered devices. Biomaterials 28 , 5148-5154. doi: 10.1016/j.biomaterials.2007.06.003

Lim, R. (2017). Concise review: fetal membranes in regenerative medicine: new tricks from an old dog? Stem Cells Transl. Med. 6, 1767-1776. doi: 10.1002/ sctm.16-0447

Magatti, M., Vertua, E., Cargnoni, A., Silini, A., and Parolini, O. (2018). The immunomodulatory properties of amniotic cells: the two sides of the coin. Cell Transplant. 27, 31-44. doi: 10.1177/0963689717742819

Magatti, M., Vertua, E., De Munari, S., Caro, M., Caruso, M., Silini, A., et al. (2016). Human amnion favours tissue repair by inducing the M1-to-M2 switch and enhancing M2 macrophage features. J. Tissue Eng. Regen. Med. 11, 2895-2911. doi: $10.1002 /$ term. 2193

Malhotra, C., and Jain, A. K. (2014). Human amniotic membrane transplantation: different modalities of its use in ophthalmology. World J. Transplant. 4, 111121. doi: $10.5500 /$ wjt.v4.i2.111

Mamede, A. C., Carvalho, M. J., Abrantes, A. M., Laranjo, M., Maia, C. J., and Botelho, M. F. (2012). Amniotic membrane: from structure and functions to clinical applications. Cell. Tissue Res. 349, 447-458. doi: 10.1007/s00441-0121424-6

Mansour, S. C., Pena, O. M., and Hancock, R. E. (2014). Host defense peptides: front-line immunomodulators. Trends Immunol. 35, 443-450. doi: 10.1016/j.it. 2014.07.004

Mao, Y., Hoffman, T., Johnson, A., Duan-Arnold, Y., Danilkovitch, A., and Kohn, J. (2016). Human cryopreserved viable amniotic membrane inhibits the growth of bacteria associated with chronic wounds. J. Diab. Foot Compl. 8, 23-30.

Mao, Y., Hoffman, T., Singh-Varma, A., Duan-Arnold, Y., Moorman, M., Danilkovitch, A., et al. (2017). Antimicrobial peptides secreted from human cryopreserved viable amniotic membrane contribute to its antibacterial activity. Sci. Rep. 7:13722.

Mao, Y., Singh-Varma, A., Hoffman, T., Dhall, S., Danilkovitch, A., and Kohn, J. (2018). The effect of cryopreserved human placental tissues on biofilm formation of wound-associated pathogens. J. Funct. Biomater. 9:3. doi: 10.3390/ jfb9010003

Mei, C., Yang, W., Wei, X., Wu, K., and Huang, D. (2019). The unique microbiome and innate immunity during pregnancy. Front. Immunol. 10:2886. doi: 10.3389/ fimmu.2019.02886

Mencucci, R., Menchini, U., and Dei, R. (2006). Antimicrobial activity of antibiotictreated amniotic membrane: an in vitro study. Cornea 25, 428-431. doi: 10. 1097/01.ico.0000214207.06952.23
Moore, R. M., Mansour, J. M., Redline, R. W., Mercer, B. M., and Moore, J. J. (2006). The physiology of fetal membrane rupture: insight gained from the determination of physical properties. Placenta 27, 1037-1051. doi: 10.1016/j. placenta.2006.01.002

Mühlhauser, J., Crescimanno, C., Rajaniemi, H., Parkkila, S., Milovanov, A. P., Castellucci, M., et al. (1994). Immunohistochemistry of carbonic anhydrase in human placenta and fetal membranes. Histochemistry 101, 91-98. doi: 10.1007/ bf00269354

Myntti, T., Rahkonen, L., Nupponen, I., Pätäri-Sampo, A., Tikkanen, M., Sorsa, T., et al. (2017). Amniotic fluid infection in preterm pregnancies with intact membranes. Dis. Mark. 2017:8167276.

Nejad, A. R., Hamidieh, A. A., Amirkhani, M. A., and Sisakht, M. M. (2021). Update review on five top clinical applications of human amniotic membrane in regenerative medicine. Placenta 103, 104-119. doi: 10.1016/j.placenta.2020. 10.026

Oxlund, H., Helmig, R., Halaburt, J. T., and Uldbjerg, N. (1990). Biomechanical analysis of human chorioamniotic membranes. Eur. J. Obstet. Gynecol. Reprod. Biol. 34, 247-255. doi: 10.1016/0028-2243(90)90078-f

Palanker, N. D., Lee, C. T., Weltman, R. L., Tribble, G. D., Van Der Hoeven, R., Hong, J., et al. (2019). Antimicrobial efficacy assessment of human derived composite Amnion-Chorion Membrane. Sci. Rep. 9:15600.

Para, R., Romero, R., Miller, D., Panaitescu, B., Varrey, A., Chaiworapongsa, T., et al. (2020). Human $\beta$-defensin-3 participates in intra-amniotic host defense in women with labor at term, spontaneous preterm labor and intact membranes, and preterm prelabor rupture of membranes. J. Matern. Fetal. Neonatal. Med. 33, 4117-4132. doi: 10.1080/14767058.2019.1597047

Ramuta, T. Z., Starčič Erjavec, M., and Kreft, M. E. (2020). Amniotic membrane preparation crucially affects its Broad-spectrum activity against uropathogenic bacteria. Front. Microbiol. 11:469. doi: 10.3389/fmicb.2020.00469

Ramuta, T. Z., Tratnjek, L., Janev, A., Seme, K., Starčič Erjavec, M., and Kreft, M. E. (2021). The antibacterial activity of human amniotic membrane against multidrug-resistant bacteria associated with urinary tract infections: new insights from normal and cancerous urothelial models. Biomedicines 9:218. doi: 10.3390/biomedicines 9020218

Rangaswamy, N., Abdelrahim, A., Moore, R. M., Uyen, L., Mercer, B. M., Mansour, J. M., et al. (2011). [Biomechanical characteristics of human fetal membranes. Preterm fetal membranes are stronger than term fetal membranes]. Gynecol. Obstet. Fertil. 39, 373-377.

Resch, M. D., Resch, B. E., Csizmazia, E., Imre, L., Németh, J., Szabó-Révész, P., et al. (2011). Drug reservoir function of human amniotic membrane. J. Ocul. Pharmacol. Ther. 27, 323-326. doi: 10.1089/jop.2011.0007

Riau, A. K., Beuerman, R. W., Lim, L. S., and Mehta, J. S. (2010). Preservation, sterilization and de-epithelialization of human amniotic membrane for use in ocular surface reconstruction. Biomaterials 31, 216-225. doi: 10.1016/j. biomaterials.2009.09.034

Robson, M. C., and Krizek, T. J. (1973). The effect of human amniotic membranes on the bacteria population of infected rat burns. Ann. Surg. 177, 144-149. doi: 10.1097/00000658-197302000-00003

Robson, M. C., Krizek, T. J., Koss, N., and Samburg, J. L. (1973). Amniotic membranes as a temporary wound dressing. Surg. Gynecol. Obstet. 136, 904906.

Romero, R., Chaemsaithong, P., Korzeniewski, S. J., Tarca, A. L., Bhatti, G., $\mathrm{Xu}, \mathrm{Z}$., et al. (2016). Clinical chorioamnionitis at term II: the intra-amniotic inflammatory response. J. Perinat. Med. 44, 5-22.

Romero, R., Chaiworapongsa, T., and Espinoza, J. (2003). Micronutrients and intrauterine infection, preterm birth and the fetal inflammatory response syndrome. J. Nutr. 133, 1668S-1673S.

Romero, R., Espinoza, J., Gonçalves, L. F., Kusanovic, J. P., Friel, L. A., and Nien, J. K. (2006). Inflammation in preterm and term labour and delivery. Semin. Fetal. Neonatal. Med. 11, 317-326.

Santanna, L. B., Hage, R., Cardoso, M. A., Arisawa, E. A., Cruz, M. M., Parolini, O., et al. (2016). Antifibrotic effects of human amniotic membrane transplantation in established biliary fibrosis induced in rats. Cell Transplant. 25, 2245-2257. doi: 10.3727/096368916×692645

Sara, S. H., Prajna, N. V., and Senthilkumari, S. (2019). Human amniotic membrane as a drug carrier - An in-vitro study using fortified cefazolin ophthalmic solution. Indian J. Ophthalmol. 67, 472-475. doi: 10.4103/ijo.ijo_ 1336_18 
Šket, T., Ramuta, T., Starčič Erjavec, M., and Kreft, M. E. (2019). Different effects of amniotic membrane homogenate on the growth of uropathogenic Escherichia coli, Staphylococcus aureus and Serratia marcescens. Infect. Drug Resist. 12, 3365-3375. doi: 10.2147/idr.s215006

Soto, E., Espinoza, J., Nien, J. K., Kusanovic, J. P., Erez, O., Richani, K., et al. (2007). Human beta-defensin-2: a natural antimicrobial peptide present in amniotic fluid participates in the host response to microbial invasion of the amniotic cavity. J. Matern. Fetal. Neonatal. Med. 20, 15-22. doi: 10.1080/ 14767050601036212

Stock, S. J., Kelly, R. W., Riley, S. C., and Calder, A. A. (2007). Natural antimicrobial production by the amnion. Am. J. Obstet. Gynecol. 196:255.

Szukiewicz, D., Alkhalayla, H., Pyzlak, M., Watroba, M., Szewczyk, G., and Wejman, J. (2016). Human beta-defensin 1, 2 and 3 production by amniotic epithelial cells with respect to human papillomavirus (HPV) infection, HPV oncogenic potential and the mode of delivery. Microb. Pathog. 97, 154-165. doi: 10.1016/j.micpath.2016.06.010

Talmi, Y. P., Sigler, L., Inge, E., Finkelstein, Y., and Zohar, Y. (1991). Antibacterial properties of human amniotic membranes. Placenta 12, 285-288. doi: 10.1016/ 0143-4004(91)90010-d

Tambor, V., Kacerovsky, M., Lenco, J., Bhat, G., and Menon, R. (2013). Proteomics and bioinformatics analysis reveal underlying pathways of infection associated histologic chorioamnionitis in pPROM. Placenta 34, 155-161. doi: 10.1016/j. placenta.2012.11.028

Tehrani, F. A., Ahmadiani, A., and Niknejad, H. (2013). The effects of preservation procedures on antibacterial property of amniotic membrane. Cryobiology 67, 293-298. doi: 10.1016/j.cryobiol.2013.08.010

Tehrani, F. A., Modaresifar, K., Azizian, S., and Niknejad, H. (2017). Induction of antimicrobial peptides secretion by IL-1beta enhances human amniotic membrane for regenerative medicine. Sci. Rep. 7:17022.

Tenenhaus, M. (2017). The use of dehydrated human amnion/chorion membranes in the treatment of burns and complex wounds: current and future applications. Ann. Plast Surg. 78, S11-S13.

Tribe, R. M. (2015). Small peptides with a big role: antimicrobial peptides in the pregnant female reproductive tract. Am. J. Reprod. Immunol. 74, 123-125. doi: 10.1111/aji.12379

Varrey, A., Romero, R., Panaitescu, B., Miller, D., Chaiworapongsa, T., Patwardhan, M., et al. (2018). Human $\beta$-defensin-1: a natural antimicrobial peptide present in amniotic fluid that is increased in spontaneous preterm labor with intraamniotic infection. Am. J. Reprod. Immunol. 80:e13031. doi: 10.1111/aji. 13031

Verbruggen, S. W., Oyen, M. L., Phillips, A. T., and Nowlan, N. C. (2017). Function and failure of the fetal membrane: Modelling the mechanics of the chorion and amnion. PLoS One 12:e0171588. doi: 10.1371/journal.pone.0171588

Wang, X., Xie, J., Tan, L., Huo, J., and Xie, H. (2012). Epithelium of human fresh amniotic membrane has antimicrobial effects in vitro. Afr. J. Microbiol. Res. 6:5.
Wassmer, C. H., and Berishvili, E. (2020). Immunomodulatory properties of amniotic membrane derivatives and their potential in regenerative medicine. Curr. Diab. Rep. 20:31.

Yadav, M. K., Go, Y. Y., Kim, S. H., Chae, S. W., and Song, J. J. (2017). Antimicrobial and antibiofilm effects of human amniotic/chorionic membrane extract on Streptococcus pneumoniae. Front. Microbiol. 8:1948. doi: 10.3389/fmicb.2017. 01948

Yarbrough, V. L., Winkle, S., and Herbst-Kralovetz, M. M. (2015). Antimicrobial peptides in the female reproductive tract: a critical component of the mucosal immune barrier with physiological and clinical implications. Hum. Reprod. Update 21, 353-377. doi: 10.1093/humupd/dmu065

Yelchuri, M. L., Madhavi, B., Gohil, N., Sajeev, H. S., Venkatesh Prajna, N., and Srinivasan, S. (2017). In vitro evaluation of the drug reservoir function of human amniotic membrane using moxifloxacin as a model drug. Cornea 36, 594-599. doi: 10.1097/ico.0000000000001168

Yoshio, H., Tollin, M., Gudmundsson, G. H., Lagercrantz, H., Jornvall, H., Marchini, G., et al. (2003). Antimicrobial polypeptides of human vernix caseosa and amniotic fluid: Implications for newborn innate defense. Pediatric Res. 53, 211-216. doi: 10.1203/00006450-200302000-00003

Yoshio, H., Yamada, M., Yoshida, M., Takeuchi, A., Fujii, S., Kunii, Y., et al. (2005). Expression of a human cathelicidin antimicrobial peptide, LL-37, in amniotic fluid with neonatal or maternal infection. Pediatric Res. 58, 427-427. doi: 10.1203/00006450-200508000-00455

Zare Bidaki, M., Lessani, T., and Khazaie, Z. (2012). Evaluation of anti-bacterial effects of chorionic membranes in vitro. J. Birjand Univ. Med. Sci. 19 140-147.

Zelen, C. M., Snyder, R. J., Serena, T. E., and Li, W. W. (2015). The use of human amnion/chorion membrane in the clinical setting for lower extremity repair: a review. Clin. Podiatr. Med. Surg. 32, 135-146. doi: 10.1016/j.cpm.2014. 09.002

Zhang, Q., Shimoya, K., Moriyama, A., Yamanaka, K., Nakajima, A., Nobunaga, T., et al. (2001). Production of secretory leukocyte protease inhibitor by human amniotic membranes and regulation of its concentration in amniotic fluid. Mol. Hum. Reprod. 7, 573-579. doi: 10.1093/molehr/7.6.573

Conflict of Interest: The authors declare that the research was conducted in the absence of any commercial or financial relationships that could be construed as a potential conflict of interest.

Copyright (c) 2021 Ramuta, Šket, Starčič Erjavec and Kreft. This is an open-access article distributed under the terms of the Creative Commons Attribution License (CC BY). The use, distribution or reproduction in other forums is permitted, provided the original author(s) and the copyright owner(s) are credited and that the original publication in this journal is cited, in accordance with accepted academic practice. No use, distribution or reproduction is permitted which does not comply with these terms. 